\title{
"Nuevas Historias de Chiapas, Siglos XIX y XX", enero-diciembre 2004, Revista Mesoamérica, año 25, núm. 46, Plumsock Mesoamerican Studies-Centro de Investigaciones Regionales de Mesoamérica.
}

66 Nil novi sub sole. Nada nuevo bajo el sol". Con estas palabras se cierra el grupo de artículos que compone el número 46 de la revista Mesoamérica, dedicado a la historia contemporánea chiapaneca. Nada nuevo bajo el sol en palabras de Jan de Vos para referirse a la idealización del indígena desde los textos de Bartolomé de Las Casas hasta los escritos del subcomandante Marcos, y nada nuevo bajo el sol, diría yo, en cuanto al prisma con que se lee la historia chiapaneca en el volumen de referencia; afirmación que no es incompatible con el reconocimiento a la labor académica de los autores que signan el número, especialmente por la información, en algunos casos muy novedosa, que aportan. Parece un contrasentido y espero que a lo largo de las siguientes líneas logre entenderse a qué me refiero cuando hago mención a información novedosa y enfoques ya conocidos.

Iré más tarde a ello, ahora es conveniente advertir que una de las reiteraciones más expresadas, y seguramente ciertas hasta el momento, respecto a los estudios de ciencias sociales sobre Chiapas, ha sido y es la escasez de investigaciones que tienen al siglo XIX como tema. Siglo de transformaciones innegables en el continente americano, en especial las referidas a la obtención de la independencia de las colonias españolas y portuguesas, aunque alguna haya sido tan tardía como la cubana, 1898; que muestra todos los contrasentidos propios y ajenos en la construcción del Estado moderno. Los propios, a la hora de crear una institucionalidad contemporánea acorde con los tiempos, por estar unida a su pasado colonial, socialmente jerárquico por segregacionista y, de esa manera, rígido para entender a la ciudadanía, confuso en la tarea de imaginar la nueva nación. Los ajenos por verse en el espejo cóncavo de las metrópolis o de los países que eran ya centrales en el mundo, Estados Unidos y Europa occidental. De tal suerte que las dificultades para desplegar en su vertiente más política el liberalismo, a consecuencia de las restauraciones monárquicas o de los desencuentros entre grupos de poder, que adoptaron el nombre, por lo general, de liberales y conservadores; se reflejaron en el ámbito americano, y el caso mexicano no fue la excepción.

Esta especie de imitación distorsionada de la Europa reaccionaria a las propuestas políticas liberales, que habían tenido su punto álgido a finales del siglo 
XVIII con la Revolución Francesa, aunado a las dificultades para crearse una imagen propia de país, por las ideas evolucionistas y racialistas que atravesaron la concepción de las sociedades americanas, muestra cómo el siglo XIX y su prolongación natural en las primeras décadas del XX, es imprescindible para conocer, en el tiempo largo, las contradicciones históricas reflejadas en los periodos revolucionario y postrevolucionario en México y Chiapas.

La escasa, aunque de forma paulatina más sólida información sobre esta época, donde destacan obras como las de Jan de Vos, Jan Rus, Robert Wasserstrom o Rocío Ortiz, recuerda la relevancia del siglo, en especial por su desconocimiento, y anima a seguir la exploración temática y archivística, ora en su difusión, como ocurrió en el año 2002 con el Foro Internacional sobre Chiapas: de la Independencia a la Revolución, (CIESAS-ECOSURPROIMMSE(UNAM)-Facultad de Ciencias Sociales de la UNACH), celebrado en San Cristóbal de Las Casas, ora mediante publicaciones como el número dedicado al Chiapas decimonónico de la revista Mesoamérica.

Si se retoma el inicial hilo conductor de este texto, que hacía referencia a la información de los artículos y, también, a la perspectiva desde la que se interpretan, tal vez se logre aclarar cuál fue el motivo que me condujo a afirmar, parafraseando en este caso a Jan de Vos, que no había nada nuevo bajo el sol. Una pista se halla en la presentación del número suscrito por Armando J. Utrilla, W. George Lovell, Stephen E. Lewis y Jan Rus y cuyo título, "Algunas raíces del Chiapas moderno", ya anticipa parte del contenido. No resulta extraño que el levantamiento neozapatista sea un acicate comercial, aunque no creo que en esta ocasión tal fuera el motivo para justificar la salida a la luz de una obra histórica o antropológica. Sin embargo, sí el alzamiento armado es un argumento contundente para los firmantes, puesto que la "meta" propuesta "es exponer algunas raíces históricas generadoras del descontento y sentimiento profundo de injusticia que provocaron un evento tan dramático" (p. ix), motivo por el cual los artículos presentados permitirán "a los lectores apreciar mejor el contexto histórico de la conflictiva actualidad chiapaneca" (p. x). Es decir, por una parte existe la conciencia de que los hechos sociales más recientes, como con toda lógica es justo pensar desde la disciplina histórica, se establecen en procesos previos, procesos que, a manera de la prístina acumulación primitiva de capital, del vocabulario marxista, permiten generar una empresa determinada, donde en el caso chiapaneco sería de carácter revolucionario dirigida, o al menos integrada, por el grupo social más marginal, el indígena; mientras que, por otra, se reitera esa especie de excepcionalidad chiapaneca, aquella que convierte a su territorio no en un ejemplo, sino en el ejemplo de la injusticia secular y la reiterada conflictividad.

Desde esta lógica se entiende que buena parte de los artículos aborden la historia de Chiapas, una historia que se hace presente en la cotidianidad indígena o en las consignas y acciones del nuevo zapatismo; en fin, una historia de desigualdad social que se instala en el discurso como singular y que tanto histórica como antropológicamente ha seguido diversas corrientes interpretativas para recordar que las causas expresadas en cada momento dependen de los lentes utilizados para analizar la realidad. Sila lucha de clases no llegaba a Chiapas por ser una sociedad de producción feudal, según exégetas de no hace tantos años, ahora la decantación culturalista simulada con el vocabulario liberal, aunque les pese a los que desconozcan que lo utilizan, señala la inconmensurabilidad como problema y, a su debido tiempo, también como solución en el camino de imitar al más peligroso y reaccionario romanticismo.

Si cambiamos de rumbo, la revisión de los materiales de la revista que nos ocupa permite percibir, a los conocedores de la investigación social sobre Chiapas, que los trabajos que aportan documentación histórica de primera mano en buena medida no son presentados por historiadores de formación, hecho 
que no resta mérito a los textos, aunque informa de una de las peculiaridades de la historia realizada sobre Chiapas: el arribo al tema de académicos formados en otras disciplinas, especialmente de la antropología.

De las cinco "Contribuciones", así se llama el apartado, sólo dos se puede decir que son efectuadas por historiadores formados originalmente en tal carrera, aunque todas de alguna manera tienen un hilo conductor en la desigualdad social a través del enganche de trabajadores indígenas del norte de Chiapas, en el escrito presentado por Sarah Washbrook; del papel de los sirvientes en la ciudad de San Cristóbal de Las Casas, según lo expuesto por Ana María Garza Caligaris; de los disímiles caminos de ciertas localidades indígenas en la revolución explicados por Jan Rus; de las relaciones de género establecidas en las fincas de Simojovel en el estudio de Sonia Toledo y, para finalizar, del monopolio del aguardiente y las consecuencias del mismo en la explicación de Stephen E. Lewis.

En el escrito de Sarah Washbrook la novedad radica en aportar material sobre el sistema de enganche en el norte del estado de Chiapas, en contraposición con las informaciones recurrentes que se poseen de la región de Los Altos. Pichucalco, Chilón y Palenque, aunque lejanos los dos últimos del primero, son ejemplos de este sistema que la autora, no como novedad, considera una "servidumbre moderna". La supuesta política liberal de mediados del siglo XIX, representada en Chiapas por Emilio Rabasa y sus sucesores, entre ellos su hermano Ramón, no respondía a los criterios políticos liberales, aunque se siga insistiendo en dicha liberalidad. Tal vez la confusión estriba en la confrontación con el clero y la liberalización de ciertas tierras en posesión de indígenas e iglesia católica, sin embargo, habría que preguntarse hasta qué punto se puede seguir hablando de liberalismo para aquellos años, aunque los actores políticos así se llamaran. Las medidas económicas no respondían al ejercicio de la libre empresa y la libre circulación de mano de obra, y las medidas políticas no tuvieron cercanía al liberalismo heredero de la Revolución Inglesa ni de la Ilustración. Más bien responden al modelo que J. Ramón González Ponciano ha caracterizado como "modernización regresiva" para el caso guatemalteco, y que la autora denomina "modernización conservadora" (p. 25), en el que las corrientes del positivismo se imbrican con el evolucionismo más racialista para constituirse en las bases de un pensamiento que construyó una ciudadanía segregadora, por haber sido originariamente segregada, misma que facilitará un liberalismo económico, también suigeneris, dispuesto a supeditar la libertad económica en aras de un despegue empresarial inexistente, pues la acumulación se producía a través de materias primas exportables, comercializadas por los mismos explotadores foráneos.

Si el enganche es considerado una servidumbre, el texto de Ana María Garza Caligaris habla de otra servidumbre, aquella que se muestra en la ciudad de San Cristóbal de Las Casas, concretamente de personas procedentes, sobre todo, del barrio de Cuxtitali. Si el texto previo es novedoso por la ubicación geográfica, el de Garza lo es por lo mismo, al centrarse en la muy nombrada y poco estudiada Ciudad Real colonial; también por la elección del tema en un contexto urbano. Aunque no serán las únicas novedades del artículo, puesto que la utilización de documentación judicial, hasta ahora escasamente explorada para el estudio de la historia chiapaneca, abre vías de sumo interés, especialmente si se toma en cuenta el potencial existente en el Archivo General del Poder Judicial de Chiapas, ubicado en Tuxtla Gutiérrez.

Del artículo de Ana María Garza, construido con información de fuentes primarias, me llaman la atención varios aspectos, y no como los únicos posibles. Uno de ellos se refiere a la afirmación que efectúa en el párrafo inicial. Señala que "El imaginario político y cultural dominante de la época veía en la ley uno de los símbolos de la modernidad, impulsora de la civilización 
y el desarrollo económico" (p. 28). Tal afirmación, que no está desencaminada, también tiene otra lectura si lo que se pretende demostrar, como afirma en las reflexiones finales, es que la legislación quería mantener el régimen de servidumbre en territorio chiapaneco. Digo esto porque si algo es conocido en el periodo medieval europeo es la legislación no sólo en materia de servidumbre, por ello hay que recordar los contratos de vasallaje que se establecían entre siervos y señores, también las prácticas y símbolos que los confirmaban. En el mismo periodo histórico existía, en ciertas localidades, "libres" para el uso de los dominios comunes de tierra, y las sanciones y castigos para sus infractores. Lo que pretendo afirmar es que no sólo la llamada en el artículo "modernidad" se preocupó de la legislación, sino que lo anterior más parece un resabio tardomedieval, ${ }^{1}$ al menos en lo legislativo, con paradojas tan marcadas como la posibilidad que tenía la servidumbre de defenderse ante los tribunales de la ciudad alteña. Por ello, si la legislación era una tapadera para la explotación personal en el trabajo doméstico, innegable y asumido en Chiapas hasta la actualidad por propios y foráneos aunque se pueda negar con argumentos de escasa solvencia moral, habría que preguntarse hasta dónde los ejemplos del artículo que muestran cómo se defendieron los sirvientes, con éxito algunos según se constata en documentación de los juzgados, no sería una contradicción respecto a la servidumbre generalizada en el estado que el primer artículo muestra. Es decir, si la servidumbre estaba generalizada en el estado de Chiapas por qué sólo se defendían los sirvientes de la ciudad o, por qué se les permitía defenderse a ellos y no a los del campo. Sin

${ }^{1}$ Sin ser un análisis desde la perspectiva del materialismo dialéctico, Arno J. Mayer, La persistencia del Antiguo Régimen. Europa hasta la Gran Guerra, Alianza Editorial, Madrid, 1984, mostró cómo la prolongación de formas políticas y sociales no modernas es perceptible hasta entrado el siglo XX en Europa. poder responder a estas preguntas, el seguimiento de la documentación sobre el tema promete más novedades, referidas a la servidumbre en la ciudad y al papel de las mujeres en la misma.

El siguiente artículo firmado por Jan Rus continúa una tradición, se podría considerar ya, establecida por él mismo a través de sus estudios sobre San Juan Chamula. Su lógico repudio al funcionalismo culturalista de ciertas escuelas norteamericanas que realizaron investigaciones en suelo chiapaneco - hay que recordar que participó en el proyecto Harvard liderado por Evon Z. Vogt - le hizo volver la vista a la historia como soporte fundamental de la etnografía. La historia oral, complementada al igual con fuentes primarias, ha permitido dotar a ciertas localidades indígenas de un pasado, alejado de cualquier tentación mística. Por lo tanto, ni los indígenas son elegidos de Dios como gustan considerarlos ciertos proyectos iluminados que circulan por Chiapas desde hace décadas, algunos con el beneplácito de académicos; ni pasivos receptores de su realidad histórica, forma que permite a otros, como de manera acertada señala Jan Rus, afirmar que al no participar en el desarrollo de acontecimientos que debieron interesarles para el futuro de su sociedad no han tenido ni tienen derecho a quejarse, argumento que otorga a la denominada peculiaridad cultural la responsabilidad de tal actitud.

La explicación de Rus, en cierta medida, utiliza similares ideas ya expuestas en obras previas que tratan el caso de la revolución chiapaneca — de nuevo la excepcionalidad local, es decir, la guerra civil entre élites, los indígenas como botín y un contrasentido a lo expuesto con anterioridad, la desconexión maya no ubicada en su propia forma de relación entre localidades y hablantes de lenguas del tronco lingüístico común, sino "en la hostilidad de los ladinos con respecto a su movilización" (p. 59). 
En el fondo la historia de Chiapas, o así lo comprende la historiografía, es una continua reiteración del maniqueísmo cristiano y su interpretación se ejemplificaría en el complejo de Poncio Pilatos; todos nos lavamos las manos porque la culpa siempre es del otro. Los ladinos al acusar a los indios de los males locales, los indios y sus aliados, estos últimos divergentes dependiendo de la época al acusar a los ladinos de todas las perversiones humanas posibles.

La dispar trayectoria revolucionaria, o al menos del periodo que se conoce como revolución en México, de Chamula, Chenalhó, Zinacantán y fincas habitadas por indígenas como eran entonces Los Chorros, Tanaté y Acteal, ofrece ejemplos al autor del vaivén de las políticas locales, atravesadas por el interés de controlar los municipios, especialmente los problemáticos, mediante medidas que sesgarán su autonomía al quedar sometidos a municipios ladinos. Esta reacción ladina, que resume Rus en el concepto neoporfirismo, tendrá también distintas respuestas en las localidades elegidas, situación que demuestra la escasa validez de la explicación étnica sin tomar en cuenta otras variables sociales. En resumen, no reaccionaron por ser tsotsiles de la misma forma, lo hicieron como cualquier ser humano en coyunturas políticas y sociales diversas, de manera, por lo tanto, también diversa.

Las fincas de Simojovel llevan años siendo exploradas en su vertiente antropológica e histórica por Sonia Toledo, quien ya es la especialista por méritos propios del municipio y región de estudio. En esta entrega de investigación ahonda en la historia oral para demostrar cómo los "lazos que unían a patrones y trabajadores eran múltiples... Así se generaron vínculos afectivos, complejos y contradictorios, de lealtad, temor, respeto, odio, agradecimiento, amor y desengaño. Estas relaciones entretejidas con las de tipo económico crearon en la región "a (sic) un complicado entramado social" (p. 89). En efecto, la autora presenta un entramado que complejiza la simplista percepción de finqueros frente a mozos; desalmados propietarios frente a inocentes trabajadores. Por el contrario, las referencias a la "economía moral", acuñada por Edward P. Thompson, o a la "violencia simbólica", expresada por Pierre Bourdieu para indicar la situación vivida en Simojovel, muestran las prácticas paternalistas y los mecanismos en los que se sostenían las relaciones patrón-empleado también patrón-cliente-, aunque la autora, y los lectores, deberían preguntarse cuál hubiera sido el modelo económico propuesto si todo lo que lleva el sello liberal es rechazado, todavía en la actualidad, por estar ligado a la explotación capitalista, y la propiedad también lo es como soporte fundamental del proyecto económico liberal. Lo que queda, sin despreciar el modelo comunista, sería una supuesta, y nunca existente, comunidad ideal de campesinos indígenas, reclamada como el modelo a seguir seguramente porque nadie sabe cómo funcionaría.

El último artículo que compone la sección "Contribuciones" está firmado por Stephen E. Lewis, especialista en la educación pública en Chiapas durante el periodo postrevolucionario. Seguramente es el texto más novedoso por el tema de estudio, siempre conocido pero no tratado o al menos no publicado, me refiero a la construcción del monopolio de la producción de alcohol por los hermanos Pedrero. Lewis. Se basa, principalmente, en el informe coordinado por Julio de la Fuente que mandó a realizar el Instituto Nacional Indigenista (INI) en la década de los años cincuenta del pasado siglo. Ese informe, junto a otras referencias bibliográficas le permiten armar un primer acercamiento al hecho que significó la creación de una considerable fortuna familiar, prolongada en el tiempo a través de múltiples negocios; además de que apunta los cambios, obligados, en la producción agraria de ciertas regiones de Chiapas y, al mismo tiempo, significa un repaso al papel de las instituciones estatales y los individuos que las componen. 
El texto, por la novedad de la información reflejada en el informe coordinado por Julio de la Fuente, aporta vías múltiples para el trabajo histórico, pero también antropológico sobre un caso que por conocido, repito, sigue en espera de un seguimiento más extenso.

La revista, además de la sección principal, revisada hasta ahora en los cinco artículos que la componen, incluye tres más divididas en "Proyectos de investigación", "Fuente documental" y "Ensayo".

De los primeros abren Dolores Palomo y Andrés Aubry, quienes llevan tiempo en sus trabajos de investigación, Palomo con las cofradías en el siglo XIX y Aubry en temas diversos que involucran a la Iglesia y a los indígenas, aunque se refiera a los negros de Ciudad Real en relación con el templo de San Nicolás. Cierra la antropóloga española Pilar Sanchiz, quien narra la construcción de un proyecto de investigación incipiente entre mujeres cabezas de familia en la periferia de San Cristóbal de Las Casas.

La revista concluye su acercamiento a Chiapas con dos artículos que por su distinta naturaleza, llaman la atención. El primero de Justus Fenner por ser un recuento de guías y archivos, locales, nacionales e internacionales que recogen información sobre el siglo XIX chiapaneco. La ingrata y poco reconocida labor de recuperación y clasificación de archivos llevada a cabo por el autor desde hace casi dos décadas, tiene en el artículo una recompensa segura al facilitar la consulta de los neófitos investigadores que quieran ver en Chiapas, y concretamente en el Chiapas decimonónico, su tema de investigación.

El último trabajo, con el que se inició este escrito, muestra al Jan de Vos incisivo y sucinto que se conoce por sus primeras obras históricas sobre Chiapas, así como al también brillante crítico de fuentes de Los Enredos de Remesal. ${ }^{2}$ De manera breve, pero precisa, repasa la idealización de los indígenas chiapanecos en las obras de Bartolomé de Las Casas, B. Traven, un colectivo tseltal de los años setenta y el subcomandante Marcos. En tiempos distintos, en circunstancias históricas no equiparables, los cuatro sitúan, por motivos y propósitos divergentes, a los indígenas como el ejemplo a seguir por el resto de la sociedad que les rodea, incluso son modelo para el resto del mundo, siguiendo la huella que autores como Montaigne y Rousseau legaron a sus futuros lectores.

"La comunidad zapatista, tal como es representada en los discursos de Marcos y los comunicados del CCRI, es una utopía, un sueño, cuyo retrato obedece a exigencias ideológicas y estrategias políticas” (p. 226). Esta cita resume lo que el ensayo pregona, que en ningún momento de la historia ha existido una comunidad ideal indígena. Recordarlo, en palabras de Jan de Vos, demuestra que siempre hay tiempo para rectificar, para decir aquello que, por obvio, no se considera políticamente correcto en ciertas coyunturas históricas.

Final circular del camino de un número especial de la revista Mesoamérica que recuerda la labor ingente que en materia histórica queda por hacer en Chiapas y sobre Chiapas, a la vez que convoca, del mismo modo, a pensar caminos distintos, veredas escabrosas e incorrectas políticamente, a desandar si es necesario; en definitiva, a mirar siempre la realidad con la otra mirada, con la que ofrecen los datos pero con la que aporta un Chiapas no aislado en el tiempo ni en el espacio, una entidad que forma parte del mundo, del que no ha sido ajeno aunque creamos a veces lo contrario.

\footnotetext{
${ }^{2} J a n$ De Vos, Los enredos de Remesal. Ensayo sobre la conquista de
} Chiapas, conaculta, México, 1992.

Miguel Lisbona Guillén PROIMMSE-IIA-UNAM 